\title{
UN ESTUDIANTE RUSO EN LA YESIBA DE TOLEDO EN TIEMPOS DE ASHER BEN YEHIEL, HA-ROSH
}

Es muy importante, para una penetración a fondo en la estructura interna de las comunidades judías españolas, aclarar el papel desempeñado por extranjeros que venían a estudiar a las escuelas rabínicas (yešibot) de la península '. Había un cierto enfrentamiento mental en alguno de estos estudiantes que procedían de ambientes asquenasíes cuando se enfrentaban con la tradición sefardí. La única posibilidad de acercamiento a este problema consiste en un análisis de la documentación hebrea que se ha conservado. Conviene advertir que ésta siempre es escasa y con frecuencia difícil de interpretar. En el presente artículo trataremos de analizar un caso concreto que puede resultar muy significativo. Se encuentra en las sěelot ve-tešubot, es decir, en la Responsa de Asher ben Yehiel, Klal 51, respuesta a la pregunta número 2, pág. 49.

La Responsa es un tipo de literatura rabínica estructurada en forma de preguntas y de respuestas, como la palabra indica; es en si la correspondencia que le llega a un determinado rabino, y a la que se ha dado forma de libro, conscientes de la importancia que las decisiones adoptadas por él pueden tener para generaciones venideras. Debemos también aclarar que no todos los rabinos poseyeron una correspondencia significativa; su prestigio personal influyó de modo importante en esto. Por tanto debemos señalar que las Responsas que se conservan hoy por hoy son de aquellos rabinos considerados como cabeza de su generación; es muy probable que durante los siglos medievales se compusieran otras de distintos rabinos con menor renombre, pero de las que hoy no tenemos constancia.

Asher ben Yehiel es un rabino alemán, que nace en la ciudad de Colonia, aproximadamente hacia el año 1250; tras la muerte de sus padres, su hermano Haim se hace cargo de su educación ${ }^{2}$. Se casa en 1266, con la hija de R. Shlomo ben Yodlim de Erkelenz, llamada Clara, quien pertenecía a una de las familias con más tradición rabínica dentro de Alemania. Hacia 1283 se suceden en su país natal una serie de persecuciones, tras las que Asher toma la decisión de trasladarse a otro lugar, enviando como un primer paso a su hijo Yehudá a estudiar con R. Shlomo ben Adret, a Barcelona. Sin embargo, y pese a su interés de seguirle poco tiempo después,

1 Yesibá (pl yesibot): academias donde se enseñaban estudios rabínicos.

Yitzhak BAER, Historia de los judios en la España cristiana, trad. de J.L. Lacave, Madrid 1981, II, pág. 587.

2 Harry Freedman opina que Asher ben Yehiel completó su educación con otros maestros, como R. Meir ben Baruj de Rotenburg, y otros en Francia, quizás en Troya.

H. FREEDMAN, Rabenu Asber ben Yebiel, saasuav, baiav ve-pebulay, Frankfurt 1918/1920, reed. Jerusalem 1986, pág. 21 . 
la realización de sus deseos se hace imposible, ya que su maestro, amigo y a la vez suegro de su hermano Haim, R. Meir ben Baruj de Rotenburg, fue encarcelado entre 1286 y 1290; sólo tras su liberación se sentiría con fuerzas para llevar a cabo sus planes, y esto no sería hasta el año 1303. Él, en su peregrinar por tierras europeas pasó por diferentes países, en donde pudo haberse instalado, pero sin embargo llega a Barcelona en la primavera de 1304, hospedándose en casa de ben Adret. Hacia 1305 las autoridades comunitarias judías toledanas solicitan sus servicios, convirtiéndose a partir de estos momentos, y hasta su muerte, en Rab Mayor de su famosa judería.

Entre sus principales trabajos debemos destacar: Piskei Ha-Rosh, también conocido como Halajot $\mathrm{Ha}$-Rosh, posiblemente redactado entre los años 1310 y 1327, es decir, en Toledo. Intentó en esta obra conseguir un equilibrio entre los métodos empleados para el estudio de la Torá: el sefardí y el asquenasí; en esta obra podemos distinguir dos partes bien diferenciadas: a) Versículos y b) Halajot ${ }^{3}$.

Kizur Piskei ha-Rosh, fue citada completa por uno de sus hijos, Yaacob, en una de sus obras, el Séfer ha-Ramasim, y de ahí tenemos constancia de su existencia; escrito probablemente entre 1327 y 1334, el libro de Yaacob nos lo trae de forma fidedigna.

Significados del Talmud, de la que no poseemos datos; sólo sabemos de ella a través de una cita de su hijo Yehudá.

Tosafot ha-Rosh, a las aportaciones de sus maestros alemanes, Asher añade las de los españoles (Najmánides, Maimónides, Ben adret, etc).

Horjot Haim, de la que tampoco poseemos ningún dato, sólo la conocemos a través de otra cita de uno de sus hijos, Yaacob ${ }^{4}$.

Responsa de Asber ben Yebiel (o šeelot ve-tešubot); la primera parte compuesta en Alemania, y la segunda de su mandato toledano. La mayoría de ésta fue recopilada, tras la revisión de la correspondencia paterna por su hijo Yaacob, y la última parte de la misma por un alumno cuyo nombre desconocemos; esta obra es posterior al año 1329 '.

Y ya si nos adentramos en el documento, objeto de este artículo, vemos que la naración sobre un estudiante extranjero llamado Asher (como su maestro), surge cuando Yaacob, hijo de Asher ben Yehiel, trata de explicar la postura paterna sobre la cuestión: "Cuándo es posible dar por muerto o desaparecido a un individuon ${ }^{6}$.

Asher «el ruso» es un joven ašquenasí que llega a Toledo para estudiar en la yešibá de Asher ben Yehiel, y del que recibe un título, expedido tiempo después cuando decide regresar a su país natal (así se especificaba en la carta expedida por Asher ben Yehiel)'. Tras abandonar Toledo, Asher el alumno llega a Mallorca, donde se da a conocer a otro estudiante de la yešibá toledana, oriundo de Mallorca, y al que muestra la carta concedida por Asher ben Yehiel. Indiscutiblemente el joven

3 H. FREEDMAN, págs. 85-86.

4 H. FREEDMAN, pág. 96.

, H. FREEDMAN, págs. 89-90.

6 Neuman nos relata parte de este caso en su libro: A. NEUMAN, The Jews in Spain, their social, Politician and cultural life during the Middles Ages, Philadelphia, 1942, págs. 91-92. 
asquenasí muestra con evidente orgullo la misiva firmada por Asher ben Yehiel: es una prueba contundente de haber sido discípulo de tan isigne maestro.

El mallorquín pierde, después de este primer encuentro, el rastro del joven Asher, según se nos explica en la Responsa, pero un judío sevillano llamado Shmuel le comentó al mallorquín que había conocido a un estudiante de la yešibá de Asher ben Yehiel "que parecía askenasí» ${ }^{8}$, quién llegó a Sevilla y al poco tiempo enfermó. Shmuel recibió noticias de que éste se estaba muriendo", por lo que decidió trasladarse hacia el lugar en el que Asher «el ruso» se encontraba; el sevillano declaró que aunque éste tuvo una ligera mejoría al reconocerlo, al poco tiempo falleció.

Como vemos, muchas son las lagunas que se nos plantean en este caso particular, ya que son muy escasas las noticias que poseemos de estudiantes extranjeros en las yešibot hispanas y europeas: cuál era verdaderamente el país natal de Asher el alumno, Rusia o quizás otro lugar de «Asquenás» ${ }^{10}$; qué hacía él en Toledo, había llegado a la ciudad por casualidad, por trabajo, por una persecución o atraído, tal y como parece indicar el texto, por la fama de Asher ben Yehiel; por qué llega a Mallorca; para qué viaja después a Sevilla, etc.

Según los datos que poseemos, en el siglo XVI las yešibot de Polonia eran las más conocidas, y a ellas llegaron un número elevado de alumnos de otros países de Europa ". Greyzel opina que tanto los hijos de familias pobres como la de las ricas acudían a ellas, aunque los primeros no podían permanecer mucho tiempo en ellas, ya que ellos mismos debía encargarse de su manutención ${ }^{12}$. No nos habla, sin embargo, sobre los viajes de estudiantes a las distintas yešibot españolas durante el siglo XIV, ni en otros siglos medievales.

Neuman ${ }^{13}$, uno de los pocos historiadores que nos hablan sobre este tema, opina que en cierta medida la afluencia a las yešibot hispanas dependió del devenir de los tiempos; así cuando los judíos se encontraban asentados en al-Andalus, y en sus yešibot se enseñaba en árabe, atrajo a éstas un número elevado de alumnos procedentes de países islámicos, quienes entendían el idioma en que se impartían los cursos ${ }^{14}$. En el siglo XII, con la llegada de los almohades a la península y las persecuciones que estos llevaron a cabo en ella, los judíos emigraron hacia el norte cristiano, centro a partir de estos momentos de sus yešibot. El latín-castellano sería la

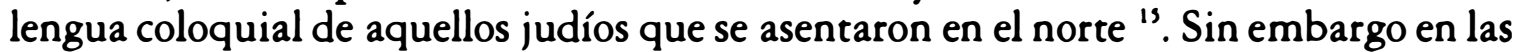
yešibot no se enseñaría en este idioma, ni tampoco se volvería al árabe, sino que los cursos se seguirían en hebreo; y es aquí cuando los estudiantes franceses, alemanes, bohemios y rusos encuentran el camino para llegar a la Península Ibérica ${ }^{16}$.

A pesar de todo creemos que el idioma debió de ser un problema para estos

8 Neuman dice que parecía alemán. A. NEUMAN, pág. 92.

19 No nos aclara dónde.

10 Abrahams nos habla del viaje de estudiantes pobres itinerantes.

Israel ABRAHAMS, Jewis life in the Middle Ages, N.Y. 1896, pág. 146.

11 S. GREYZEL, A History of the Jews, Philadelphia, 1947, pág. 452.

12 S. GREYZEL, pág. 453.

13 A. NEUMAN, pág. 93-96.

14 A. NEUMAN, pág. 93.

15 A. NEUMAN, pág. 93.

16 A. NeUMAN, pág. 93. 
estudiantes que llegaron a Sefarad, aunque al utilizarse el hebreo como lengua didáctica se solucionó en parte.

Según Neuman ${ }^{17}$, los judíos de Cataluña y Provenza eran devotos de la lengua hebrea; sin embargo existen pruebas de que en Provenza, a finales del siglo XIII, la gran mayoría de los hombres adultos no hablaban hebreo sino el idioma de su país natal ${ }^{18}$ : el hebreo, la lengua sagrada, quedó para el estudio de las materias religiosas. De todos modos, creemos que es lógico pensar que el único idioma que se empleaba en el estudio, en las yešibot, era el hebreo, pues sería imposible creer que maestros como Asher ben Yehiel, que llegaron a la península en edad madura, fueran capaces de enseñar cuestiones relacionadas con el judaísmo, bien en árabe o en el castellano del siglo XIV, cuando él mismo nos cuenta las dificultades que encontró para poder aprender ambos idiomas y poder hacerse entender por el pueblo ${ }^{19}$.

Volviendo a la cuestión que nos ocupa, diremos que este caso, de un estudiante ruso en la yešibá de Toledo, no creemos que fuera inusual, sino que muy probablemente estudiantes judíos de otras comunidades llegaron a Sefarad ${ }^{20}$.

Hemos tenido la suerte que este caso fuera mostrado como un ejemplo en la Responsa de Asher ben Yehiel, por lo que poseemos un testimonio fiel de estos hechos, cosa que no ha ocurrido con otros, y que puede deberse a dos razones: no se comentaba la llegada de nuevos estudiantes a las distintas yešibot de Sefarad por ser cosa usual, o quizás el tema no se trate porque realmente fueron escasos los estudiantes extranjeros en suelo hispano. Seguramente que en esta ocasión, al ser un rabino asquenasí Rab Mayor de una judería hispana, atrajo a un número de estudiantes de esta misma procedencia.

Yaacob, hijo de Asher ben Yehiel trae a colación el caso de Asher «el ruso», tal y como indicamos para dar un ejemplo de cuándo se debe dar por muerto a un individuo. Las circunstancias que deben concurrir: cuando la persona que atestigue dicha muerte no tenga ningún interés material en la misma (herencia, deuda...); el informante debe describir a la persona detalladamente, a ser posible deberá dar nombre, apellido, lugar de procedencia; deberá haber visto el cadáver pocas horas después de su muerte, si no podría influir la descomposición del mismo, etc.

Si todos estos requisitos son cumplidos, según Asher ben Yehiel se puede dictaminar la muerte de un individuo. Su viuda se podrá volver a casar y sus bienes podrán ser repartidos entre sus herederos.

Asher «el ruso», tras lo expuesto, fue dado por muerto.

RICA AMRÁN

Madrid

17 A. Neuman, pág. 94.

18 A. NEUMAN, pág. 94.

19 H. FREEDMAN, pág. 27

20 Neuman asegura que Asher "el ruso" llegó a Sefarad acompañado de otro alumno, Yonatán; también afirma que por aquellos tiempos vivía en Toledo un alumno de Bohemia llamado Rubén. A. NEUMAN, pág. 92. 


\section{TEXTO}

Todo depende de cómo el testigo dé el testimonio; si éste no tiene ningún interés, y nos da los datos y el nombre, entonces debemos creerle. Al hombre se le da por muerto, y si tiene mujer ésta puede volver a casarse.

Ha-Rosh trae un ejemplo de un hombre que habitaba en una montaña; un testigo afirmó, dando el nombre de esta persona, que él había muerto; fueron a dicha montaña para comprobar los datos, y pese a no encontrarse el cadáver, se le consideró como muerto y su viuda pudo contraer nuevas nupcias.

Está escrito en el Talmud Yerusalmi que si encontramos un documento donde se afirma que una determinada persona murió o fue muerta, el viudo/a puede volver a casarse. Trae un caso específico, que R. Yaacob ben Ha-Rosh recuerda: «un alumno vino a Toledo a estudiar con mi padre -dice R. Yaacob- después de un período de tiempo, él partió para su tierra natal. Otro alumno llegó a esta Yeshivá, desde Mallorca, y trajo el siguiente testimonio: en Mallorca vi un estudiante, y me mostró una carta firmada por $\mathbf{R}$. Asher (que él la trajo como prueba de la veracidad de sus afirmaciones). En la carta estaba escrito: este alumno vino a Toledo y se marcha a su tierra después de haber estado un tiempo estudiando conmigo. Después de un tiempo, encontrándome yo en Mallorca, llegó un muchacho cuyo nombre es R. Shmuel (quien vivía en Sevilla) y me comentó que un alumno que parecía ashkenasí, cuyo nombre era Rabenu Asher, y que había estudiado con $\mathrm{Ha}$-Rosh, llegó a Sevilla, donde estuvo con él un día, marchándose a continuación a otra ciudad. Poco tiempo después un señor me dijo que dicho alumno estaba próximo a morir, en seguida me dirigí hacia donde él se encontraba, quien al verme mejoró un poco, sin embargo murió al poco tiempon. 